\title{
Chapter 4 \\ The Mathematical Training of Teachers from the Point of View of Education
}

Incidentally, I dislike everything that is mere knowledge to me without extending my activity or directly invigorating me.

J. W. von Goethe (in a letter to Friedrich Schiller)

\begin{abstract}
Summary
The paper describes an approach to integrating the mathematical and educational components in teacher training which is based on elaborating educational and psychological aspects inherent in "good mathematics". This leads to a conception of informal, problem- and process-oriented presentations of elementary mathematics. The paper concludes by sketching an "elementary mathematics research program" in mathematics education.
\end{abstract}

\section{Introduction}

Since the middle of the seventies there has been a growing international discussion about what professional qualifications mathematics teachers need and what kind of training is appropriate to develop these qualifications (Bromme et al. 1981; Fletcher 1975; Otte 1979; Proceedings of ICME-4, Berkeley 1980, Chap.5; Proceedings of ICME-5, Adelaide, 1984, Theme Group 3, pp. 146-158). It is not by chance that this discussion emerged in the seventies because, at that time, societal change in many countries around the world brought discord between two quite different philosophies of teacher training: that of training teachers for the grammar school, the college, the gymnasium, the lyceum, etc. and that of training teachers for the elementary school. The first of these two philosophies put prominent emphasis on subject matter as if familiarity with subject matter per se would form the only true scientific basis of teaching; vice versa, the other concentrated on pedagogy, psychology and methods courses and considered subject matter as a more-or-less trivial aspect of teaching (cf., Heintel 1978, pp. 12-22; Krämer 1987).

The recognition that the professional knowledge of all teachers has to be some synthesis of subject matter and educational knowledge helped to transform the historic controversy between different groups of teachers and teacher training philoso-

E. C. Wittmann, Connecting Mathematics and Mathematics Education, https://doi.org/10.1007/978-3-030-61570-3_4 
phies into a structural problem of teacher training in general. As Otte (Otte 1979, pp. 114-115) comments:

Compared with other professions, the special structural problem of the teaching profession is that it does not have one "basic science" such as law for the lawyer, medicine for the physician... Scientific theory is related in two utterly different ways to the practical work of mathematics teachers: first, scientific knowledge and methods are the subject matter of teaching; second, the conditions and forms of its transmission must be scientifically founded. Thus, teaching is under far more complex pressure than other professions to justify itself against competing conceptions of scientific theories, and has to cope with far greater demands with respect to the integration of diverse dimensions in the unity of action.

Similarly it was not by chance that in the seventies mathematics education (didactics of mathematics) emerged around the world as a specific interdisciplinary field of study related both to mathematics and to the educational sciences since a specific response to this structural problem of integrating the mathematical and educational aspects of teaching had to be developed which neither mathematics nor the educational sciences could provide.

Because of the inherent complexity of issues and because of historic burdens smooth and quick solutions of this problems of integration resolving all tensions between the different aspects are not likely, and so integration should be seen as an extended process which requires both time and deliberation. It is therefore appropriate to pause from time to time and reflect on what progress has been made, what deficiencies have been observed and to consider how to proceed further. The present paper is intended as a contribution to such an evaluation.

The structure of the paper is as follows:

I will first try to establish that a genuine integration of mathematics into mathematics education and a conception of embedding mathematics courses into a truly professional teacher training program are still lacking. Following John Dewey I will next show that a genuine integration of mathematics and education can be achieved only if educational and psychological relationships and processes inherent in good mathematics are elaborated and developed. This then leads me to a conception of informal, problem- and process-oriented presentations of elementary mathematics and their role in mathematics teacher training programs. I will conclude by identifying a research program on elementary mathematics.

\section{The Problem of Integrating Mathematical and Educational aspects in Mathematics Education and Teacher Training}

The diagram in Fig. 1 has been introduced to describe the locus of mathematics education and its interrelationships with the most important fields of reference (Wittmann Wittmann 1981, p. 2). Using this diagram I would like to describe the present state of integrating mathematical, educational and practical components into mathematics education as follows:

We have "flows" of theories from mathematics, psychology and pedagogy into mathematics education. Some of these are applied to didactical problems in an eclec- 


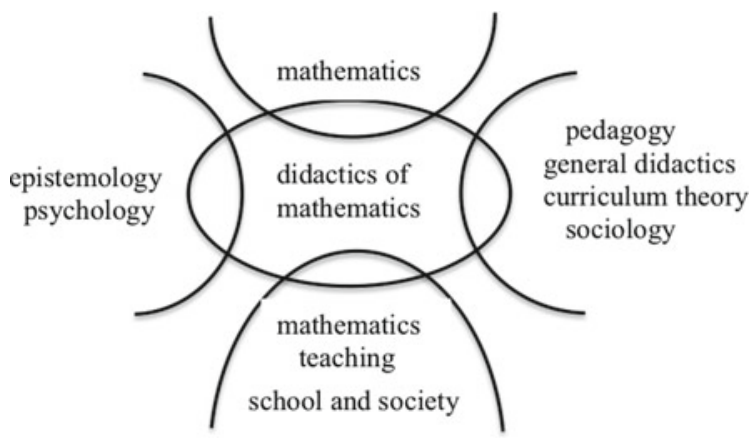

Fig. 1 Didactics of mathematics and the surrounding disciplines

tic way without, however, achieving a genuine integration. Although we can appreciate the contributions of mathematics educators to psychology I would nevertheless argue that presently research in mathematics education tends more to consuming "theories from abroad" than to producing its own "home-grown theories", to projecting its specific demands back to the related fields, and to working in these fields on its specific problems (Fig. 1).

We see a striking example of the lack of integration of mathematics into mathematics education in a recently published book by the international Bacomet-Group which set out "to consider, define, and analyse basic components of mathematics education for teachers" (cf. Christiansen et al. 1986). In a review of the book Quadling (1987, p. 188) makes the following statement:

This is clearly an important book: the international perspective, the eminence of the collaborators, the resources which have supported its production, the targeting on a teacher-educator readership all mark it out for special attention. And yet in some respects the outcome is a disappointment. However stimulating the preparatory conferences were for the contributors, to the outsider there are few signs of common purpose... There must be concern also that the subject "mathematics" is curiously relegated to the side-lines, with many issues raised by Dörfler and McLone [in their article on school mathematics] ignored in later chapters...

The situation is not very different as far as the level of teacher training is concerned. In general, the mathematical training of teachers is not systematically related to educational aspects. Very often we find a formal study of mathematics ignoring the requirements of school in, as I see it, a scandalous way (Cooney 1988; Romberg 1988). The problem is particularly serious when the mathematical, the didactical and the educational training of teachers are in the responsibility of different faculties. However, organisation alone cannot explain the lack of integration. Even at institutions where the mathematical training of teachers is in the hands of mathematics educators there is often the same formal mathematical training as is typically found in departments of mathematics. This is mainly due to the fact that many mathematics educators tend to stick to their own scientific background either in mathematics or in the educational sciences and do not seriously strive for an integration of the two worlds. 


\title{
2 The Educational Substance of Subject Matter
}

At a conference on "Trends and problems of mathematics teacher training" held in Bielefeld, FRG, Fletcher (1975, p. 217) asked the question "Is a mathematics teacher a mathematician or not?" and came to the following conclusion:

\begin{abstract}
The teacher of mathematics certainly needs to be a mathematician, and he needs to be a special sort of mathematician. He needs the general mathematical background that enables him to talk on equal terms with mathematics graduates, although he does not need some of the more specialised areas of mathematics which form part of most degree courses which are devoted exclusively to the subject. He needs a broad knowledge of applications in the world outside and in other parts of the school curriculum.

In addition the teacher needs specialist skills of his own, in the translation of mathematics from one form into another, in understanding the pattern of thinking of his pupils at various stages of development and in understanding the relevance of structural ideas in mathematics to the teaching of it. Mathematics has its own criteria of truth, and the teacher has a special relation to his profession; if the teacher does not teach from conviction he alters the nature of the teaching he gives. The mathematics teacher is not only a mathematician, he is a professional mathematician with unique responsibilities.
\end{abstract}

A biased reader might perhaps understand Fletcher's paper as a plea for the traditional subject matter philosophy of teacher training referred to at the beginning of this paper, and consequently either support or reject it emphatically. However, a careful analysis of his paper shows that Fletcher is far from neglecting the educational component in the professional knowledge of mathematics teachers. In fact the basic message of his paper is that the educational knowledge cannot be acquired in separation from mathematics. In his contribution to ICME 4 Fletcher (1983, p. 113) put it this way:

When we are teaching mathematics to prospective secondary teachers teaching method is not a subject apart. In many training institutions these two components are treated separately, but good mathematics and good methods can be studied simultaneously to the benefit of both. Let us make this our major fundamental change.

In my view, exactly this is the track we should follow in order to bring about a genuine integration between the mathematical and the educational knowledge of mathematics teachers. This perspective is further developed by reference to papers of two scholars from education and philosophy.

John Dewey (1904) wrote a fundamentally important article on the relation of theory to practice in teacher training. At that time the problems of integrating subjectmatter preparation with professional instruction and relating educational theory to student-teaching were relatively new. It proves testimony to Dewey's genius that he at once hit the crucial points. Part B, section II, of Dewey's paper is devoted to training in subject matter and its relationship to educational theory and to practice:

I turn now to the side of subject matter, or scholarship, with the hope of showing that here too the material, when properly presented, is not so merely theoretical, remote from practical problems of teaching, as is sometimes supposed... Scholastic knowledge is sometimes regarded as if it were something quite irrelevant to method. When this attitude is even unconsciously assumed, method becomes an external attachment to knowledge of subject-matter. 
It has to be elaborated and acquired in relative independence from subject-matter, and then applied.

Now the body of knowledge which constitutes the subject-matter of the student-teacher must, by the nature of the case, be organized subject-matter... it has been selected and arranged with reference to controlling intellectual principles. There is, therefore, method in subject-matter itself - method indeed of the highest order which the human mind has yet evolved, scientific method.

It cannot be too strongly emphasized that this scientific method is the method of the mind itself. The classifications, interpretations, explanations, and generalizations which make subject-matter a branch of study do not lie externally in facts apart from mind... It is necessary to recognize the importance for the teacher's equipment of his own habituation to superior types of method of mental operation. The more a teacher in the future is likely to have to do with elementary teaching, the more, rather than the less, necessary is such exercise... Only a teacher thoroughly trained in the higher levels of intellectual method and who thus has constantly in his own mind a sense of what adequate and genuine intellectual activity means, will be likely, in deed, not in mere word, to respect the mental integrity and force of children...

The present divorce between scholarship and method is as harmful upon one side as upon the other - as detrimental to the best interests of higher academic instruction as it is to the training of teachers. But the only way in which this divorce can be broken down is by so presenting all subject-matter, for whatever ultimate, practical, or professional purpose, that it shall be apprehended as an objective embodiment of methods of mind in its search for, and transactions with, the truth of things.

Of course Dewey's ideas must be seen in the context of his holistic views about the relationship of subject-matter to life and learning and about the relationship of theoretical insight to practical activity in general. Ignoring this context could again easily lead to the wrong conclusion that Dewey pleaded for trivializing educational knowledge and for restricting teacher training to subject-matter training, which is certainly the last thing he wanted. In fact, Dewey argued in favor of elaborating the educational substance of subject-matter beyond the limitations of narrow subject specialists, as we shall see in the next section.

To reflect this unified picture of mathematical and educational components, didactics of mathematics as a specific professional discipline cannot be organized on the scientific level as a field of study where mathematical, psychological, pedagogical and practical aspects of teaching are investigated separately. Rather it must be equally based on a genuine integration of mathematics and the educational sciences. In a paper delivered at the first Symposium on mathematics education held in Klagenfurt, Austria, the philosopher Peter Heintel (1978, pp. 45-46) elaborated this position very clearly:

Didactics of subject-matter means didactics rooted in subject-matter, in knowledge itself. It means analysing the subject according to didactical moments inherent or "deep-frozen" in itself.

We have to start from the fact that the knowledge inherited in the subject has been the result of learning processes of mankind and that something of this genesis is still existent. Also we have to acknowledge the fact, that all knowledge, each subject and each science represent conventional and authorized systems of language, which govern not only our relations to nature, but also our social relations... 
...Therefore taking subject matter fundamentally into account in building didactical models means breaking up the narrow boundaries of special disciplines, reconstructing "deepfrozen" learning processes, and elaborating the social use of knowledge and also its limitations.

\section{Elementary Mathematics in Teacher Training}

It goes almost without saying that the conception described above depends crucially on a proper understanding of mathematics as the subject of mathematics teaching. "Mathematics" must not be seen within the narrow boundaries of a specialised discipline which is represented exclusively by the departments of pure mathematics at the universities; rather it should be seen in the full spectrum of its relationships to science, to technology, to the humanities, and to human life. We should be reminded here of Whiteheads's famous dictum that there is only one subject matter of education, namely "Life in all its manifestations". Therefore the anemic, sterile presentations of mathematics as a closed formal system still widely in vogue around the world, are inappropriate for educational purposes. A genuine integration of the mathematical and educational aspects compels mathematics educators to develop courses which introduce mathematics as an integral part of human culture and in which preservice teachers learn mathematics as a language and like a language, not as a tacit and lonely game with "glass pearls". As a consequence there courses must present mathematics in a "mixed form" or as "interpreted mathematics" (cf. Dörfler and McLone 1986, p. 60), and they must concentrate on the more elementary fields of mathematics because those have the richest cultural interrelationships and therefore the strongest educational impact.

The pragmatic proposal presented here is this:

Every teacher training program should involve courses in elementary mathematics which are designed with respect to didactical, pedagogical and psychological aims. These courses should cover the whole mathematical training for primary teachers, for teachers of the lower secondary level a major part of it. These courses in elementary mathematics may be characterized as follows:

(1) The courses should be explicitly related to the content of school mathematics and give a coherent treatment of relevant parts of elementary algebra (number theory and combinatorics), elementary geometry, calculus, and elementary stochastics. However, they should go well beyond school mathematics in both depth and breadth.

(2) The courses should be rich in relationships to history, culture and the real world and should involve applications to mathematical phenomena in the environment of school students.

(3) The courses should be organized in a genetic way, i.e. they should be problemand process-oriented. Theory should be developed through problems from inside and outside of mathematics with heuristics included in a prominent manner. 
(4) The style of these courses should be informal ("inhaltlich-anschaulich") and involve a variety of means of representation using, in particular, concrete materials, pictures, diagrams, etc. This can be done in a sound way while avoiding sloppy and incorrect presentations. Logic must not be suspended in elementary mathematics.

(5) The courses should allow for a variety of teaching/learning formats, e.g. investigation, exposition, reading, and cooperative learning which involves discussion and a growing student awareness of their own learning processes.

(6) The courses will deal implicitly with the teaching of school mathematics, but they need not do so explicitly. This may be reserved for special didactical courses which are closely related to the courses in elementary mathematics. Although there are interesting attempts in primary teacher training to integrate mathematics and didactics within one course (cf. Goffree 1982; Davis 1987). I am personally in favor of a split for a pragmatic reason given already in Dewey's paper: “... the mind of a [teacher] student cannot give equal attention to both at the same time."

Comparing these characteristics with recent research on the nature of professional knowledge and mathematical literacy of mathematics teachers (Steinbring 1988; Romberg 1988) there can be no doubt that courses in elementary mathematics form an indispensable part of the professional training of mathematics teachers. In my view they represent what Fletcher $(1975$, p. 206) has called the teacher's "special mathematical expertise".

There is insufficient space in this paper to describe a course in elementary mathematics along the lines detailed above, but I would like at least to provide a glimpse of what elementary mathematics in this sense should be like. Let me give two examples.

The first one is from elementary algebra. My colleague Gerhard Müller and I are presently developing a mathematics course on arithmetic for primary teacher students in which counters and arrays of dots are used as a basic means of representation. For example, we follow a nice idea of Winter (1983) in deriving the divisibility rules. Students are given a place value chart with boxes for ones, tenths, hundreds etc. and are asked to solve a series of problems, as in the following:

(a) Find numbers up to 1000 which can be represented by 1, 2, 3, 4, 5 or 6 counters as in Fig. 2.

(b) Determine the remainders of each of these numbers with respect to the divisor 9.

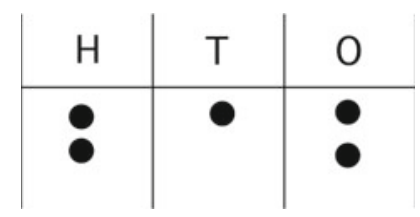

Fig. 2 Representing numbers by counters on the place value chart 
The investigation shows that the remainders depend only on the number of counters, and the question arises why this is so. Answer: Moving a counter one box up or down changes the number by $9(=10-1)$ units and therefore the remainder does not change. This is an argument, both rigorous and general, which proves the divisibility rule for 9 . By working with counters and searching for patterns all elementary divisibility rules can be discovered and proved in this manner.

This little piece of substantial mathematics contains problems, theorems and sound proofs, and is clearly related to the teaching of arithmetic at the primary level. Further, it gives primary teacher students an important opportunity for investigation, provides them with a familiar means of representation (i.e., counters) which is fundamental for the primary level, and can serve as a model of how mathematics is developed. Since counters and the place value chart have also played an important role in history, this example meets all characteristics of the elementary mathematics courses listed above.

My second example is from elementary geometry. In my own course at the University of Dortmund I have included the following unit on mirrors (cf., Wittmann 1987, Chap. 1.1 and 3.2):

Starting from physical experiments with plane mirrors the concept of reflection is introduced and some inequalities are derived (Fig. 3).

The first two inequalities follow from the equal length of symmetric segments and the triangle inequality applied on the triangles BSC and BTA'.

Figure 3 (i) supports also the proof of a useful theorem that is an extension of the base angle theorem and its converse: The side opposite the bigger one of two angles of a triangle is longer than the side opposite the smaller angle and vice versa the angle opposite the longer one of two sides is bigger than the angle opposite the smaller side.

(i) Mirror inequality:
$\overline{A C}>\overline{B C}$

(ii) Heron's inequality:

$\overline{A T}+\overline{T B}>\overline{A S}+\overline{S B}$

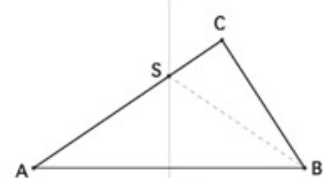

$A^{\prime}$.

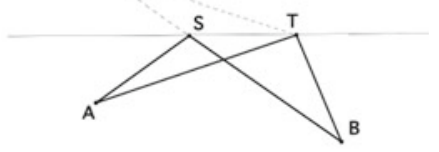

(iii) Distance inequality:

$\overline{A T}>\overline{A F}$

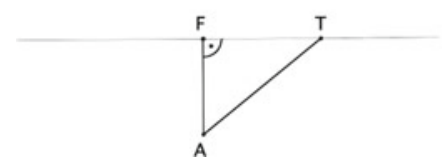

Fig. 3 Geometric inequalitites 
The third inequality is a consequence of this theorem as the right angle in triangle is always the biggest angle.

These simple inequalities have surprisingly many applications.

Next the parabola, the ellipse and the hyperbola are defined by means of the well-known envelope constructions (Fig. 4).

Using the above inequalities tangents of these curves can be determined and then the focal properties are easy to prove. The transfer from the parabola to the ellipse and the hyperbola is a very nice exercise in heuristics. The unit ends with a study of technical applications of curved mirrors, e.g. telescopes, where combinations of different mirrors are used, and the kidney lithotripter developed a few years ago by the German company Dornier (Fig. 5).
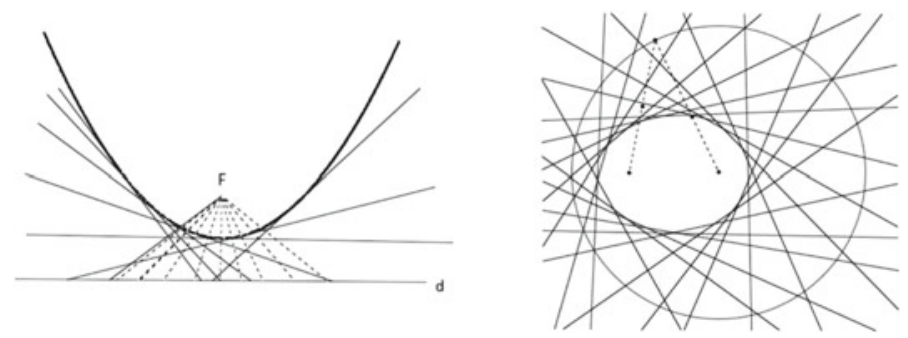

Fig. 4 Envelope constructions of the parabola and the ellipse

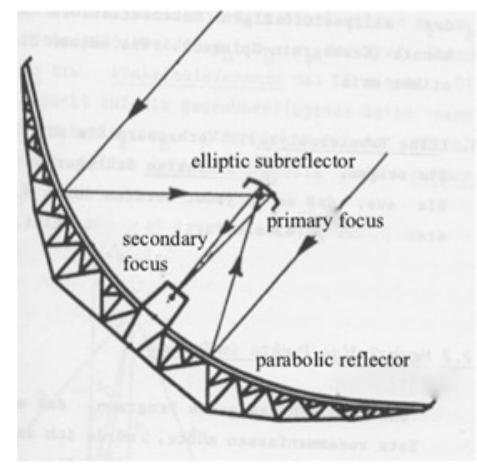

Gregory antenna

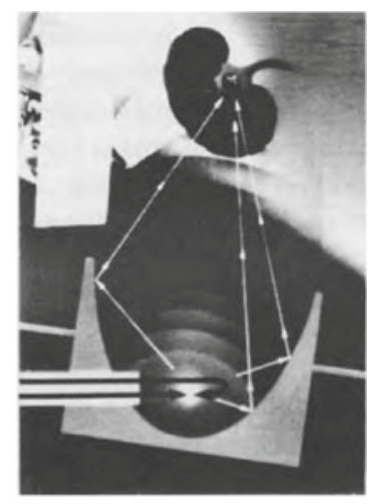

Extracorporeally induced destruction of kidney stones by means of shock waves

Fig. 5 Applications of elliptic and parabolic mirrors 
Checking this unit against the items listed above shows that it meets all the required properties.

It can be seen that teaching proper didactical courses will be enhanced by courses in elementary mathematics if each one is tuned to the other; e.g., the divisibility rule for 9 could be re-met in a didactical course under the perspective of teaching it to children. Winter (1985) has reported on a teaching unit with 10 year-old-children which provides excellent material for didactical studies. Equally the example on mirrors can easily be related to the teaching of geometry at the secondary level. In this connection I would like to refer to the "philosophy of teaching units" (cf., Wittmann 1984; Becker 1986) which recommends the use of teaching units in a systematic way in order to relate different components of teacher training to one another.

\section{The Elementary Mathematics Research Program of Mathematics Education}

However reasonable and convincing the idea of integrating mathematical and educational aspects in teacher training may appear in principle, the difficulties of putting it into practice on a large scale should not be underestimated. In order to overcome them hard and extended research is needed.

Experiences in writing a textbook on elementary geometry for teacher training (cf., Wittmann 1987) have convinced me that the development of courses on elementary mathematics in the sense described above cannot be considered a more-or-less simple appendix to mathematics; quite on the contrary, it presupposes the conceptual reconstruction of elementary parts of mathematics from an educational point of view. Accordingly we have here a truly interdisciplinary task for which elements of mathematics, its history, its applications, aspects of epistemology, psychology, pedagogy and the mathematics curriculum have to be merged together. At first sight one might get the impression that this variety of aspects is an arbitrary mixture, but such is not the case. Behind the seeming diversity there is a common perspective-the genetic principle of mathematics education (cf., Wittmann 1981, Chap. 10) which unites all of the following:

(1) a genetic view on mathematics as expressed by Felix Klein and Henri Poincaré around the turn of this century and revived in our time by, for example, Freudenthal and Lakatos,

(2) Jean Piaget's genetic epistemology and Soviet psychology based on the concept of activity as the background of a great deal of work being done in the psychology of mathematics, and

(3) genetic theories of personal development and social interaction developed in both in the Western and Eastern World.

Although the literature of mathematics and its applications as well as the literature of mathematics education are full of beautiful examples of elementary mathematics which are consistent with the genetic view, nevertheless, a coherent, homogeneous, and comprehensive conception of elementary mathematics is lacking and therefore 
the position of elementary mathematics in teacher training is not as respected as it should be (cf. also, Fletcher 1975, p. 206). In my opinion this gap can only be filled if elementary mathematics is made a focus of didactical research. Therefore elementary mathematics is suggested as an important research context in mathematics education, with the vision to establish elementary mathematics as a kind of "natural mathematics", natural in the sense of "natural language" and "natural numbers".

In particular, this research should involve:

- the foundation of informal mathematics as a self-consistent level of mathematical thought beyond mathematical formalism (cf., Hanna 1983; Müller and Wittmann 1988),

- the development of a "grammar" of non-symbolic means of representation (cf., Sawyer 1964),

- the development of operative proofs (cf., Semadeni 1974; Kirsch 1979; Walther 1984),

- the development of informal theories within contexts (cf., "didactical phenomenology", Freudenthal 1983; Walther 1984; "interpreted mathematics", Dörfler and McLone 1986).

In this way elementary mathematics could become a substantial body of didactic knowledge with a unique profile which could compete in coherence and systematics with formal mathematics.

The pursuit of this research program will certainly not open a royal road to mathematics education but it will likely move us closer to an integration of mathematical and educational aspects within mathematics education and would greatly contribute to making our discipline an efficient professional background for mathematics teachers.

\section{References}

Becker, J.P.: The role of teaching units in improving mathematics education. In: Paper Presented at the Fourth Japan-China-Conference on Mathematics Education, Yamanashi University, Kofu, Japan, September 8-22, 15 p. (1986)

Bromme, R., et al.: Perspektiven für die Ausbildung der Mathematiklehrer. IDM-Reihe Untersuchungen zum Mathematikunterricht, Bd. 2, Köln, Aulis (1981)

Christiansen, B., et al.: Perspectives on Mathematics Education. Reidel, Dordrecht (1986)

Cooney, T.J.: The issue of reform: what have we learned from yesteryear? Math. Teach. 81(5), 352-363 (1988)

Davis, R.B.: Theory and practice. J. Math. Behav. 6, 97-126 (1987)

Dewey, J.: The Relation of Theory to Practice in Education. National Society for the Scientific Study of Education. Third Yearbook, Part I, pp. 9-30. Public School Publishing Co., Bloomington (1904)

Dörfler, W., McLone, R.: Mathematics as a school subject. In: Christiansen, et al. (eds.) Perspectives on Mathematics Education, pp. 49-97. Dordrecht, Reidel (1986)

Fletcher, T.J.: Is the teacher of mathematics a mathematician or not? Schriftenreihe des IDM Bielefeld 6, 203-218 (1975)

Fletcher, T.J.: The Mathematical Preparation of Secondary Teachers - Content and Method. In: Zweng, M., et al. (eds.) Proceedings of ICME, Boston, vol. 4, pp. 111-113 (1983)

Freudenthal, H.: Didactical Phenomenology of Mathematical Structures. Reidel, Dordrecht (1983) 
Goffree, F.: Wiskunde and Didactiek, vol. 1, 2. Groningen (1982)

Hanna, G.: Rigorous Proof in Mathematics Education. Ontario Institute for Studies in Education, Toronto (1983)

Heintel, P.: Modellbildung in der Fachdidaktik. Eine philosophisch-wissenschaftstheoretische Untersuchung, Klagenfurt (1978)

Kirsch, A.: Beispiele für prämathematische Beweise. In: Dörfler, W., Fischer, R., (Hrsg.) Beweisen im Mathematikunterricht, pp. 261-274. Wien, Stuttgart (1979)

Krämer, E.: Zur Problematik der Lehrerbildung. In: Proceedings of the Conference on Didactical Problems in the University Education of Mathematics Teachers, pp. 19-32. Univerzita Karlova, Praha (1987)

Otte, M.: The Education and the Professional Life of Mathematics Teachers. New Trends in Mathematics Teaching, vol. IV, pp. 107-132. UNESCO, Paris (1979)

Quadling, D.: Review of Christiansen et. al., Perspectives on Mathematics Education. Zentralblatt für Didaktik der Mathematik 87/5, 187-188 (1987)

Romberg, T.A.: Can teachers be professionals? In: Grouws, D.A., Cooney, T.J., Jones, D. (eds.) Perspectives on Research on Effective Mathematics Teaching, vol. 1, pp. 224-244. NCTM, Reston (1988)

Sawyer, W.W.: Vision in Mathematics. London (1964)

Semadeni, Z.: The Concept of Pre-mathematics as a Theoretical Background for Primary Mathematics Teaching. Warsaw (1974)

Steinbring, H.: Nature du savoir mathematique dans la pratique de l'enseignement. In: Laborde, C. (ed.) Actes du Premier Colloque Franco-Allemand de Didactique des Mathématiques et de l'Informatique, pp. 307-316. La Pensée Sauvage, Grenoble (1988)

Walther, G.: Action proofs versus illuminating examples? For Learn. Math. 4, 10-12 (1984)

Winter, H.: Prämathematische Beweise der Teilbarkeitsregeln. Mathematica didactica 6, 177-187 (1983)

Winter, H.: Neunerregel und Abakus - schieben, denken, rechnen. Mathematik lehren 11, 22-26 (1985)

Wittmann, E.C.: Grundfragen des Mathematikunterrichts. Braunschweig (1981)

Wittmann, E.C.: Teaching units as the integrating core of mathematics education. Educ. Stud. Math. 15, 25-36 (1984)

Wittmann, E.C.: Elementargeometrie und Wirklichkeit. Einführung in geometrisches Denken. Vieweg, Braunschweig (1987)

Wittmann, E.C., Müller, G.N.: Wann ist ein Beweis ein Beweis? In: Bender. P. (Hg.) Mathematikdidaktik: Theorie und Praxis. Festschrift für Heinrich Winter. Berlin, Cornelsen (1988). (English version: Wittmann, E.C., Müller, G.N.: When is a proof a proof? Bulletin de la Societé Mathématique Belgique, Serie A, Tome XL II, pp. 15-42 (1990))

Open Access This chapter is licensed under the terms of the Creative Commons Attribution 4.0 International License (http://creativecommons.org/licenses/by/4.0/), which permits use, sharing, adaptation, distribution and reproduction in any medium or format, as long as you give appropriate credit to the original author(s) and the source, provide a link to the Creative Commons license and indicate if changes were made.

The images or other third party material in this chapter are included in the chapter's Creative Commons license, unless indicated otherwise in a credit line to the material. If material is not included in the chapter's Creative Commons license and your intended use is not permitted by statutory regulation or exceeds the permitted use, you will need to obtain permission directly from the copyright holder.

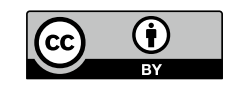

